\title{
NUDGING THE POWERFUL:
}

\section{Reflecting on How to Make Organisations Comply with Environmental Regulation}

\author{
Amy Lawton*
}

\begin{abstract}
This article argues that there is a role for nudging the powerful in the environmental sphere. Like humans, businesses and organisations are not rational. Like humans, this could be exploited using choice architecture (more commonly known as 'nudging'). Drawing on an empirical study of the Carbon Reduction Commitment (CRC), this article will explore how social norms can be used to shape organisational behaviour, with a view towards 'nudging' them towards more environmentally friendly behaviour. More specifically, social norms can be used to encourage collaboration or competition between regulatees, provided a connection to reputation can be made.
\end{abstract}

\section{Keywords}

CRC; environmental taxes; nudging; reputation; carbon emissions.

Humans are not rational. Flaws in our decision-making can be exploited. This shaping of the decisions that we make is known as choice architecture: but is perhaps better known as nudging. ${ }^{1}$ This is an article concerned with the potential for nudges to drive environmentally beneficial behaviour by organisations. It does so by using an empirical study of the Carbon Reduction Commitment (CRC) as a springboard to ask hard questions about whether social nudges can be integrated into environmental regulatory policy to improve environmental outcomes. Such an approach is novel in that nudges have so far been conceived and implemented in relation to choices made by individual humans and to date there has been no significant literature on nudging the 'powerful'. ${ }^{2}$ In other words, nudging organisations. This article is therefore unique in the sense that it asks the question of whether we can nudge the powerful and whether we can frame the choices available to businesses to highlight a greener path. This article argues that organisations are irrational on two, core levels: a macro (organisational decision-making cannot escape the organisational setting) and micro (environmental decision-makers working alone or in very small teams). The CRC study illustrates that there are additional drivers that can be used to exploit this irrationality and shape environmental behaviour in organisations. One such way is the use of social norms, or nudging.

English legal scholars, in the main, have not been proponents of nudging as a means of social and state control. ${ }^{3}$ Despite the traditional criticisms of nudging and specific obstacles related to nudging CRC participants, the fact that nudging the powerful could even be a possibility is a concept that has not

\footnotetext{
* Amy Lawton, Lecturer in Law, Lancaster University, a.lawton1@lancaster.ac.uk

${ }^{1}$ Richard Thaler and Cass Sunstein, Nudge: Improving Decisions about Health, Wealth and Happiness (Penguin 2009) 4.

${ }^{2}$ Although there has been discussion of corporations being the choice architects. A useful overview of this can be found in a Radio 4 special broadcast on nudging: BBC Radio 4, 'Nudge Nudge' (BBC,

$22^{\text {nd }}$ October 2018) <https://www.bbc.co.uk/programmes/b0b90xc6 > accessed 15 January 2019. For example, whilst businesses were not raised once in relation to being the subjects of nudging, examples of them being 'nudgers' was provided. Fast food chain 'LEON', for instance, has removed the ' $f$ ' signs from its menu to make its customers less cost aware (at 20 minutes).

${ }^{3}$ See, for example: Karen Yeung, 'Nudge as Fudge' (2011) 75MLR 122; Robert Baldwin, 'From Regulation to Behaviour Change: Giving Nudge the Third Degree' (2014) 77MLR 831; David Campbell, 'Cleverer than Command?' (2017) 26Social and Legal Studies 111.
} 
been considered in academic literature to date. Companies are not individuals. The resources and expertise that they possess far outstrip those of an individual and companies utilise these resources during decision-making. Therefore, the flaws that can be targeted in individuals (for example inertia and the use of defaults) ${ }^{4}$ cannot be exploited in companies. Nonetheless, companies are not perfectly rational. They cannot consider every possibility that arises from a decision; and personal values can still creep into corporate decision-making. ${ }^{5}$

This article draws on interview data to show how reputation and public image are a particular point of weakness for companies and how these can be exploited using social norms. Specifically, regulatees can compete with their peers in a bid to be 'seen to be green', ${ }^{6}$ and sectors come together to collaborate and pool resources. In this study of the CRC scheme, three key themes emerged from interviewees: collaboration, competition, and connection. This article argues that social nudges can incite collaboration and competition, but only if there is enough connection between the behaviour and the public. This unexplored subject is important, as it provides us with an opportunity to consider an alternative approach to environmental protection and a potentially wider role for nudging alongside other regulatory instruments.

This article unfolds in three parts. First, the study that underpins this article will be outlined; as well as a brief introduction on the CRC provided. Bounded rationality and nudging literature will be explored to demonstrate that companies are not perfectly rational. This article will then draw on the wealth of data provided by the CRC study participants to demonstrate how social norms could be used as additional drivers alongside more traditional regulatory approaches.

\subsection{The CRC Study}

Introduced in 2009, the CRC is a tax-like environmental scheme that was designed to reduce corporate energy consumption as part of the wider UK climate change toolkit. The CRC was initially introduced in the CRC Energy Efficiency Scheme Order 2010 as a trading scheme under the powers held within s.44 Climate Change Act 2008. ${ }^{7}$ It was a complex scheme. In essence, it provided a financial driver that added a cost onto energy consumption - making an economical case for energy reduction. More specifically, the CRC added a fixed price onto each kWh of electricity consumed, making electricity consumption costlier for business. This operated through an allowances system, which were required to be purchased and surrendered by CRC participants to a value equal to their energy consumption. There was a reporting element that ran alongside the financial driver and required participants to

\footnotetext{
${ }^{4} \mathrm{~A}$ default is the choice that applies if no decision is made. A default rule is the status quo - it is the decision that applies if the human does not make any further decisions. Thaler and Sunstein (n 1) 38-39.

${ }^{5}$ See section 2 of this article.

${ }^{6}$ Compare this to competition-based regulation, as seen in Wendy Wagner, 'Using Competition-Based Regulation to Bridge the Toxics Data Gap' (2008) 83 Indiana L 629. Here, Wagner explains competition-based regulation as follows: 'in competition-based regulation, regulators provide a venue for the "better" chemicals to prosper at the expense of the "worse" (untested or unnecessarily risky) chemicals by adjudicating claims of environmental superiority', 640. Nudging is subtler than this; it would not entail the regulator producing specific certificates of 'environmental superiority' for products (641). The notion of competition is, however, similar here. Compare this also to the notion of the social license, as discussed in Neil Gunningham, Robert Kagan and Dorothy Thornton, Shades of Green: Business, Regulation and the Environment (Stanford UP 2003), which is linked to 'reputation capital'. 'Those with reputation capital, it is argued, will most readily gain access to the means by which to make future profits' (53). Here, we are discussing the role of the state in shaping corporate choices, rather than the accrual of green brownie points for leverage (see also 152).

${ }^{7}$ The CRC Energy Efficiency Scheme Order 2010, SI 2010/768.
} 
report on their energy consumption annually. It is important to note here that compliance with the CRC did not require a participant to reduce its energy consumption; if the participant reported their energy consumption and purchased the correct number of allowances, they were compliant with the scheme. Energy reduction was therefore a behaviour that was beyond compliance.

Significantly, for the purposes of this article, the CRC also had two reputational and social drivers attached to it: an (abandoned) Performance League Table (PLT) and the publication of penalties by the Environment Agency. Following numerous reforms and two public consultations over the complexity and burdensome nature of the scheme, the CRC was abolished in 2016 and came to an end in April 2019. Whilst the CRC scheme is now over, the lessons learnt from its time can be applied to a wider understanding on how organisations respond to policy measures - and in this case how organisations might be nudged towards different behaviours.

Empirical work in environmental law is still limited, ${ }^{8}$ and, as such, this study provides a source of original data on an environmental scheme operating in the UK. Empirical research into environmental law 'provides a window into the role of law more generally' and to date, 'researchers know relatively little about how the design of environmental law affects behavior'. ${ }^{9}$ In addition, whilst 'empirical research has so far succeeded in identifying these varied pressures that bear on compliance and beyond-compliance behavior, the challenge in the future will be to explain better how these multiple factors interact with each other'. ${ }^{10}$

This study draws on 31 interviews with participants, advisors and the regulator for the CRC scheme. The CRC was a mandatory scheme for those that qualified, and it targeted middle business consumers of energy - iethose that are not too energy intensive to qualify for the EU Emissions Trading Scheme, ${ }^{11}$ but those that consume considerable energy nonetheless. ${ }^{12}$ All but one of the participants interviewed held the job title of 'Energy Manager' or its equivalent. ${ }^{13}$ The advisors were comprised of both solicitors and consultants. The interviews for this study were undertaken in two phases: a pilot study; and a main study. ${ }^{14}$ This article draws on both sources of data. The initial pilot study of 8 interviews was undertaken between October and December 2015. The interviewees for the pilot study were all universities participating in the CRC and were selected at random to be contacted. This was done by collating each university participant, identified through the CRC 2013-2014 Annual Report Publication

\footnotetext{
${ }^{8}$ See for example Steven Vaughan, “The Law is my Data”: The Socio-Legal in Environmental Law' (OUP Blog, 4 September 2017) <https://blog.oup.com/2017/09/socio-legal-in-environmental-law/ > accessed 25 April 2018. Empirical environmental law scholarship does exist, however, and examples can be seen in the Journal of Environmental Law: Margherita Pieraccini, 'Rethinking Participation in Environmental Decision-Making: Epistemologies of Marine Conservation in South-East England' (2015) 27JEL 45; Bettina Lange and Mark Shepheard, 'Changing Conceptions of Rights to Water? An Eco-Socio-Legal Perspective' (2014) 26JEL 215; Bettina Lange, 'National Environmental Regulation? A Case-study of Waste Management in England and Germany' (1999) 11) JEL 59.

${ }^{9}$ Cary Coglianese and Catherine Courcy, 'Environmental Regulation' in Peter Cane and Herbert Kritzer (eds), The Oxford Handbook of Empirical Legal Research (OUP 2010) 450, 459.

10 ibid 459.

${ }^{11}$ The CRC Energy Efficiency Scheme Order 2013, SI 2013/1119, Schedule 1, paragraph 28(1).

12 The threshold was 6,000 MWh of energy. The CRC Energy Efficiency Scheme Order 2013, SI 2013/1119, Article 3.

${ }^{13}$ This is an important point and will be discussed in section 2.1.

${ }^{14}$ Helen Sampson, 'Navigating the Waves: the Usefulness of a Pilot in Qualitative Research.' (2004) 4Qualitative Research 383.
} 
(ARP), ${ }^{15}$ onto a spreadsheet and using a random number generator to generate the corresponding university to be contacted. ${ }^{16}$ Out of 50 universities contacted by email, 8 positive responses were received, and the interviews took place both over the phone and face-to-face. The interviews were semi-structured, using an interview schedule as a basis. ${ }^{17}$

Following this pilot, a further 23 interviews were completed between January and April 2016. Initially, recruitment for these interviews was done at random by letter (again using the ARP and a random number generator). Despite 90 letters being sent to participants of the CRC, no positive responses, and only one negative response was received. This was disappointing; ${ }^{18}$ but such are the risks in doing empirical work. I then contacted the Environment Agency, the administrator for the scheme, and asked for an advert to be placed in the CRC regulatee newsletter. ${ }^{19}$ This approach was more fruitful. The interviewees for the main part of the study were therefore self-selecting. Whilst their selfselecting nature means they do not form a representative sample of those involved in the CRC, their viewpoints still provide a useful insight into a failed regulatory scheme. In terms of demographics, interviewees came from a range of public and private sectors including: higher education; construction; utilities; retail; transport and logistics; hospitality; the NHS; and local authorities. There is also great variation in the size of participants as the data pool ranges from organisations that only just fall under the scheme, to emitters that have been in the top 10 of the PLT. The organisations emanate from across the UK and are not geographically limited.

Overall, the interviews were between 40 and 75 minutes in length, with an average of 50 minutes. The key issues addressed in the interviews centred around the interviewees' perceptions of the CRC as a regulatory scheme and included topics such as its complexity and ability to drive behavioural change. Importantly for this article, the interviewees were not asked directly for their opinions on nudging or wider concepts of reputation, the topic of social drivers arose on its own accord in both the pilot and main study data. Indicators of social norms arose across the different roles of interviewee as well; and so, universities (pilot study), CRC participants, consultants, solicitors and the regulator all point to a role for nudging. As such, interviewees specifically discussed reputation (10 interviewees); competition (9 interviewees); and League Tables (25 interviewees) during interviews. This would indicate a potential role for nudging in environmental regulation. Even where specific, related words were not raised, wider discussion in 19 interviews was coded and also pointed towards a role for social norms. ${ }^{20}$ It is this social side to the CRC that will be explored to argue that exploiting the social nature of the CRC could be important to enhance the positive behavioural change impacts that the CRC could have.

\footnotetext{
${ }^{15}$ Environment Agency, 'CRC Energy Efficiency Scheme Annual Report Publication 2013/14' (20 November 2014), available via: <https://www.gov.uk/government/publications/crc-annual-report-publication-2013-to2014> accessed 21 August 2019.

${ }^{16}$ Jane Ritchie and others, 'Designing and Selecting Samples' in Carol McNaughton Nicholls, and Rachel Ormston, (eds) Qualitative Research Practice: A Guide for Social Science Students and Researchers (Sage 2013). ${ }^{17}$ Steinar Kvale, Doing Interviews (Sage 2008); Kathryn Roulston, Reflective Interviewing: A Guide to Theory and Practice (Sage 2010).

18 Yehuda Baruch and Brooks C Holtom, 'Survey Response Rate Levels and Trends in Organizational Research' (2008) 61Human Relations 1139.

${ }^{19}$ Following an interview with the regulator, a short advert of the study was placed into a participant email update in March 2016. This advert contained contact details, which allowed participants to come forward if they wanted to be interviewed.

${ }^{20}$ Amanda Coffee and Paul Atkinson, Making Sense of Qualitative Data: Complimentary Research Strategies (Sage 1996); and Tehmina Basit, 'Manual or Electronic? The Role of Coding in Qualitative Data Analysis' (2003) 45Educational Research 143.
} 


\section{Nudging Literature}

The term nudging first appeared in the seminal work of Cass Sunstein and Richard Thaler, ${ }^{21}$ and was introduced in 2009 as an alternative to command and control regulation. A wealth of literature on the subject has developed. ${ }^{22}$ Nudging has become a rich field of scholarship in a short amount of time.

Thaler and Sunstein define a nudge as follows:

A nudge, as we will use the term, is any aspect of the choice architecture that alters people's behaviour in a predictable way without forbidding any options or significantly changing their economic incentives. To count as a mere nudge, the intervention must be easy and cheap to avoid. Nudges are not mandates. ${ }^{23}$

Nudging therefore uses choice architecture to alter decisions to a more preferred choice without removing any of the choices from the decision-maker. ${ }^{24}$ Therefore, this article does not consider the pure, financial driver that is the tax of the CRC (ie the payment made to the Treasury for the purchase of allowances) as there is no choice involved in paying this cost. Instead, this article will consider more subtle methods of exploiting the bounded rationality of individuals (and, as will be argued, the bounded rationality of organisations).

The subject of nudging has received considerable political attention in the US, ${ }^{25} \mathrm{EU},{ }^{26}$ and by the OECD. ${ }^{27}$ In the UK, former Prime Minister David Cameron set up the Behavioural Insights Team (BIT), perhaps better known as the 'nudge unit', and which is now a separate company that researches and tests nudges ${ }^{28}$ It has been labelled 'the global poster child for the latest behavioural turn in policy and regulation' ${ }^{29}$ The Unit has developed and built upon Thaler and Sunstein's work in Nudge, UK policy

\footnotetext{
21 Thaler and Sunstein (n 1).

22 See, for example above (n 3).

23 ibid 6.

${ }^{24}$ Cass Sunstein, Simpler, The Future of Government (Simon and Schuster 2013) 39. For more on the two systems, see: Daniel Kahneman, Thinking Fast and Slow (Penguin 2012) Part 1.

${ }^{25}$ Office of the Press Secretary, 'Presidential Memorandum Regarding Regulatory Review' (Office of the Press Secretary 23 April 2009) <https://obamawhitehouse.archives.gov/the-press-office/presidential-memorandumregarding-regulatory-review> accessed 20 June 2019; Cass Sunstein also headed up the regulatory division of the Office of Information and Regulatory Affairs (in the US Whitehouse), between 2009 and 2012; although his time there was not without criticism, see: John Broder, 'Powerful Shaper of US Rules Quits, With Critics in Wake' The New York Times (New York, 3 August 2012)

<http://www.nytimes.com/2012/08/04/science/earth/cass-sunstein-to-leave-top-regulatory-post.html> accessed 21 September 2017.

${ }^{26}<$ http://ec.europa.eu/consumers/archive/conferences/behavioural economics2/programme en.htm> accessed 21 September 2017.

27 OECD, 'Behavioural Economics and Environmental Policy Design' (OECD July 2012).

${ }^{28}$ Albeit in partnership with the Cabinet Office. See The Behavioural Insights Team, 'About Us' $<$ http://www.behaviouralinsights.co.uk/about-us/> accessed 21 August 2019. See also 'Government Launches Competition to Find a Commercial Partner for the Behavioural Insights Team' $<$ https://www.gov.uk/government/news/government-launches-competition-to-find-a-commercial-partnerfor-the-behavioural-insights-team> accessed 21 August 2019.

${ }^{29}$ Murieann Quigley and Elen Stokes, 'Nudging and Evidence-Based Policy in Europe: Problems of Normative Legitimacy and Effectiveness' in Alberto Alemanno and Anne-Lise Sibony (eds), Nudge and the Law: A European Perspective (Hart 2015) 61.
} 
documents, ${ }^{30}$ and wider academic literature; ${ }^{31}$ and developed the following acronym in relation to nudges: E - Easy; A - Attract; S - Social; T - Timely (otherwise known as EAST). ${ }^{32}$ Nudging is therefore well established in UK policy.

Wider criticisms have been raised against nudging by the advocates of more traditional regulation. I am conscious that in addressing nudging the powerful, behavioural economics might be being stretched 'to solve problems it wasn't meant to address' ${ }^{33}$ Baldwin argues that nudging lacks the transparency that is seen in more traditional forms of regulation. ${ }^{34}$ There is also a trade-off in autonomy when using nudging in favour of the desired behaviour, as the decisions are shaped for the decision-maker to bypass conscious individual judgment. Nudges can therefore be an expression of the capacity of individuals and their ability for 'autonomous and responsible decision-making'. ${ }^{35}$ In Campbell's words: 'nudging does not treat citizens as children; it treats them as mugs'. ${ }^{36}$ However, organisations are not individuals. The fact remains, though, that organisations (whilst bounded) do possess a significant amount more resources than individuals could ever hope to.

There has been academic interest in nudging for the environment. ${ }^{37}$ The first link between nudges and the environment dates back to the start of the field, with Thaler and Sunstein dedicating a chapter to 'saving the planet'. ${ }^{38} \mathrm{Now}$, nudging has a presence in core environmental law textbooks. ${ }^{39}$ Quigley and Stokes have also considered the role of nudging, individuals and 'green consumerism'; ${ }^{40}$ these 'green nudges' aim to promote environmentally friendly behaviour amongst individuals. ${ }^{41}$ The interplay between environmental taxation and nudging has also been considered at an individual level. ${ }^{42}$ The academic focus on nudges in the environmental field has centred on the role of defaults, ${ }^{43}$ which are mechanisms that aim to change the default option, that is, the status quo if a proactive decision is not

\footnotetext{
${ }^{30}$ Institute for Government, 'MINDSPACE: Influencing Behaviour through Public Policy' (2010).

${ }^{31}$ See for example Robert B Cialdini, Influence: The Psychology of Persuasion (Rev Ed, Collins Business 2007).

32 Behavioural Insights Team (BIT), 'EAST: Four Simple Ways to Apply Behavioural Insights' (2014) <http://www.behaviouralinsights.co.uk/publications/east-four-simple-ways-to-apply-behavioural-insights/> accessed 16 March 2017, 4.

${ }^{33}$ George Loewenstein and Peter Ubel, 'Economics Behaving Badly', New York Times (New York, 14 July 2010) <https://www.nytimes.com/2010/07/15/opinion/15loewenstein.html> accessed 1 March 2018.

${ }^{34}$ Baldwin (n 3) 844.

${ }^{35}$ Yeung (n 3) 146; see also Karen Yeung, 'The Forms and Limits of Choice Architecture as a Tool of Government' (2016) 38 Law and Policy 186, 191-193.

${ }^{36}$ Campbell (n 3) 123.

${ }^{37}$ Robert Lee, 'Regulation and Localism' (2011) 23 Env Law Management 166; Rachel Croson and Nicolas Treich, 'Behavioural Environmental Economics: Promises and Challenges' (2014) 58 Environmental and Resource Economics 335, 337.

38 Thaler and Sunstein (n 1) Ch 12.

${ }^{39}$ Stuart Bell and others, Environmental Law (9 $9^{\text {th }}$ Ed, OUP 2017) 259-260.

${ }^{40}$ Quigley and Stokes (n 29).

${ }^{41}$ Rachel Croson and Nicolas Treich, 'Behavioural Environmental Economics: Promises and Challenges' (2014) 58 Environmental and Resource Economics 335.

42 Dora Costa and Matthew Kahn, “Energy Conservation “Nudges” and Environmentalist Ideology: Evidence from a Randomized Residential Electricity Field Experiment' (2013) Journal of the European Economic Association 680.

${ }^{43}$ See for example: Aristeidis Theotokis and Emmanouela Manganari, 'The Impact of Choice Architecture on Sustainable Consumer Behavior: The Role of Guilt' (2015) $131 \mathrm{~J}$ of Business Ethics 423; Johan Egebark and Mathias Ekstrom, 'Can Indifference Make the World Greener?' (2016) 76 Journal of Environmental Economics and Management 1.
} 
made. ${ }^{44}$ Nonetheless, nudging has been described to be 'at least a useful additional tool' in the environmental arena. ${ }^{45}$

However, whilst there is a plethora of literature on nudging individuals, the same cannot be said for nudging businesses. ${ }^{46}$ The core tenet of nudging is that humans are incapable of full rationality and making fully informed and considered decisions. As I will argue, this this can apply equally to businesses as it does to individuals - in this way, businesses suffer from bounded rationality just as humans do and so nudging can move away from only being applied to the individual or consumer.

\subsection{Nudging the powerful - bounded rationality}

Thaler and Sunstein split the world into 'humans' and 'econs'. ${ }^{47}$ 'Econs' can think through all possibilities and information, in order to come to an informed decision; they are driven by incentives rather than emotion. ${ }^{48}$ Prior to the language of 'nudging', Thaler and Sunstein found the seeds of their ideas in behavioural economics. In particular, both drew upon the concept of bounded rationality in their earlier work, ${ }^{49}$ the idea that our cognitive limitations 'preclude us from thinking deeply about more than a small fraction of the issues that bear on our values, behavior, and welfare' that feed into human decision-making. ${ }^{50}$ Traditional nudging targets 'individual behaviour', therefore, rather than behaviour in an organisational setting. ${ }^{51}$ It exploits the specific, psychological weaknesses of humans in the sense that we are not rational beings. If interpreted at face value, it would mean that the concept of nudging would translate poorly into the business context. As non-individuals, businesses do not suffer from the same psychological weaknesses, or 'cognitive limitations' as humans. They are vastly more resourced, and they enjoy an organisational setting. Decision making on the corporate scene also tends to be done within teams, or with managerial oversight - i.e. decisions are not made by individuals. This does not mean, however, that businesses are fully rational. They too suffer from bounded rationality and this could be exploited by nudging.

The concept of bounded rationality, pioneered by Herbert Simon, accepts that there are constraints on a human's ability to make rational decisions; unlike traditional economic theory:

Traditional economic theory postulates an 'economic man', who, in the course of being 'economic' is also 'rational'. This man is assumed to have knowledge of the relevant aspects of his environment, which, if not absolutely complete, is at least impressively clear and voluminous. He is assumed also to have a well-

\footnotetext{
${ }^{44}$ For more information on status quo and defaults, see Thaler and Sunstein (n 1) 37-38.

${ }^{45}$ Felix Ekardt and Jutta Wieding, 'Nudging and Environmental Law' in Klaus Mathis and Avishalom Tor, Nudging - Possibilities, Limitations and Applications in European Law and Economics (Springer 2016), 261.

${ }^{46}$ A good example is Peter John and others Nudge, Nudge, Think, Think: Experimenting with Ways to Change Civic Behaviour (Bloomsbury 2013) - a book dedicated to looking at how individuals can be exploited through nudging. Unsurprisingly, it did not discuss nudging corporations.

47 Thaler and Sunstein (n 1) 7.

48 ibid 7, 9.

${ }^{49}$ See, for example: Timur Kuran and Cass Sunstein, 'Availability Cascades and Risk Regulation' (1999) Stan L Rev 683; Christine Jolls, Cass Sunstein and Richard Thaler, 'A Behavioral Approach to Law and Economics' (1998) 50(5) Stan L Rev 1471.

${ }^{50} \mathrm{Ibid}$, Kuran and Sunstein, 704.

${ }^{51}$ Businesses as the target of nudges has not been raised in Thaler and Sunstein's work. As mentioned above, whilst businesses and nudging have been explored in the context of businesses being the choice architects, the concept has not yet explored the possibility of nudging businesses. See also: Martin Lodge and Kai Wegrich, Managing Regulation: Regulatory Analysis, Politics and Policy (Palgrave MacMillan 2012) 114.
} 
organized and stable system of preferences, and a skill in computation that enables him to calculate, for the alternative courses of action that are available to him, which of these will permit him to reach the highest attainable point on his preference scale. ${ }^{52}$

This language echoes well with Thaler and Sunstein's 'econ', the person that chooses 'unfailingly well'. ${ }^{53}$ The econ, or economic and rational person, is the opposite of humans. ${ }^{54}$ Instead, as Simon argues, it is impossible for a human to know all information and all consequences that flow from a decision, a fact that removes humans from objective rationality. ${ }^{55} \mathrm{~A}$ popular example of this can be seen in a game of chess. ${ }^{56}$ During a game, it would be impossible for a human to consider all the possible moves that would stem from a single move; let alone consider all the possible moves that could stem from all possible moves. In this way, therefore, rationality is bounded.

The organisations that are part of the CRC also make decisions. In particular, the Energy Managers who take responsibility of the CRC are generally responsible for both regulatory compliance and for the wider, environmental agenda for the business. They not only ensured corporate compliance with the CRC, but they also advocate for energy efficiency measures to be introduced in companies. In this vein, the rationality of organisations is bounded in two core ways. First, the organisations as a whole cannot possibly consider every possible choice available to them when faced with a decision; they do so in line with policies, allowing for nudges to influence policy at a macro level. Second, decisionmakers under the CRC generally work alone or in very small teams. This limits the organisational setting of any decision that is made and opens the door for a micro influence. Whilst the constraints on business rationality may not be the same as those on human rationality, they are nonetheless not 'econs'. In this way, there are two core, potential weaknesses in a company's rationality that will be explored. At a broader level, nudges could also be used to drive corporate policy. More specifically, social norms could be used to influence the individual decision-maker in an organisational setting (in this case, the Energy Manager).

\section{Macro influence - the bounded rationality of corporate organisations}

Whilst the teams of energy managers in businesses appear to be small, this does not remove the fact that they are rooted in an organisational setting - there is at least some oversight from senior management and there are overarching company strategies. The CRC energy managers are therefore not making individual, personal decisions regarding the CRC. Their decisions are influenced by company policy and priorities; and the decision-makers have organisational resources rather than individual resources. One possible approach to influence corporate decision-making would therefore be to drive changes in corporate policy. In addition, despite the resource advantages that companies have over individuals, organisations are not rational entities. ${ }^{57}$ The theory of bounded rationality, as

\footnotetext{
52 Herbert Simon, 'A Behavioural Model of Rational Choice' (1955) Quarterly Journal of Economics 99, 99.

53 Thaler and Sunstein (n 1) 7.

${ }^{54}$ Indeed, Campbell argues that 'a comparison of the merits as general theories of neo-classical economics and behavioural economics is so much in the favour of the former that one can hardly say that a comparison can actually be drawn' Campbell (n 3) 120.

${ }^{55}$ Herbert Simon, Administrative Behavior: A Study of Decision-Making Processes in Administrative Organization (3rd ed, Free Press, 1976) 67.

${ }^{56}$ Herbert Simon, 'Theories of Bounded Rationality' in C MgGuire and Roy Radner (eds) Decision and

Organization (North Holland 1972); cited also in John Conlisk, 'Why Bounded Rationality?' (1996) 34 J Econ Literature 669, 679.

57 Simon, Administrative Behavior (n 55) 13.
} 
outlined above, applies as equally to organisations as it does to individuals. ${ }^{58}$ This section will consider whether there is the potential for nudges to be used at a macro-policy level; to highlight greener paths for corporate policymaking.

Simon highlights that organisational activity 'is group activity'. ${ }^{59}$ This means that some of the autonomy is taken from the individual decision-maker to implement organisational values and policy in a predetermined decision-making process. ${ }^{60}$ This limitation of autonomy and the organisational nature of companies is what makes applying nudges to them difficult. We are no longer dealing with individuals. Rationality requires the individual decision-maker to consider all possible decisions and choose the best one. ${ }^{61}$ Even in an organisational setting, this is not physically possible and so rationality is bounded. ${ }^{62}$ As such, Simon put forward the theory of 'satisficing', whereby decision makers consider a limited number of decisions and choose the first possible satisfactory one. ${ }^{63}$ They choose a decision that is 'good enough'. ${ }^{64}$ 'Satisficing', therefore, is a label applied to an approach to rationality 'in situations where complexity and uncertainty make global rationality impossible. ${ }^{65} \mathrm{As}$ human rationality is bounded by a limited information processing ability, ${ }^{66}$ so is administrative (or business) rationality:

If individuals satisfice rather than maximize, all the more so do governments and other large organisations. Organizational decision-making processes hardly meet the requirements of classical rationality. Organizations have multiple goals, defined in terms of aspiration levels; they search until satisfactory courses of action are found; they resort to feedback rather than systematically forecasting future conditions and they use "standard operating procedures and rules of thumb" to make and implement decisions. ${ }^{67}$

Through 'satisficing', businesses also take shortcuts with their decision-making. Just as humans are not rational in the sense that they do not consider the consequences of every possible choice, so are businesses. This irrationality in individuals has been exploited through shaping choice architecture and using 'nudges'. The shortcuts that businesses take in decision-making can also be exploited just as nudging has exploited the cognitive limitations of individuals. By shaping choice architecture to provide a 'satisfactory' course of action that is visible to businesses, regulators can influence the decisions that businesses are making by highlighting or emphasising particular choices. If a nudge can influence policy, then this provides the structure for future decision-making in a company. This potential irrationality is, in fact, possible because there is a very small number of staff that deal with the CRC.

\section{Micro and macro influence - the limited nature of corporate energy teams}

\footnotetext{
${ }^{58}$ Robert Keohane, After Hegemony: Cooperation and Discord in the World Political Economy (Princeton UP 2005) 114.

${ }^{59}$ Simon, Administrative Behavior (n 55) 8.

60 ibid.

${ }^{61}$ Conlisk (n 56) 675.

${ }^{62}$ Simon uses the game of chess to illustrate his argument here, by stating that it would be impossible for a player to consider all possible moves. He then goes on to say: 'If the game of chess, limited to its 64 squares and six kinds of pieces, is beyond exact computation, then we may expect the same of almost any real-world problem...', in Herbert Simon, 'Invariants of Human Behavior' (1990) 41) Annual Review of Psychology 1, 6.

63 Simon, 'Theories of Bounded Rationality' (n 56) 168.

${ }^{64}$ Melvin Eisenberg, 'The Limits of Cognition and the Limits of Contract' (1995) 47Stan L Rev 211, 215.

65 Simon, 'Theories of Bounded Rationality' (n 56) 170.

${ }^{66}$ Eisenberg (n 64) 214.

${ }^{67}$ Keohane (n 58) 114.
} 
The limited nature of CRC teams (and environmental teams more widely) means that there is the potential to shape the choices of the individual decision-maker in an organisational setting. During the main stage of interviews, I asked participants: Is it just you working on CRC, or do you have a team? For most interviewees, they (with the job title of 'Energy Manager', 'Environmental Manager' or equivalent) ${ }^{68}$ were working alone or in a team of two. The biggest CRC team was a team of four (CRC P8). A solicitor also added:

With many larger clients, there tends to be a person that is responsible for sustainability that deals with CRC and related things, so it tends to be quite a centralised function rather than something that many people are involved in. Most clients tend to have their expert which is usually one or two people. (CRC S2)

CRC staff units in the businesses involved in the scheme tend to be very small. Whilst the Energy Managers were responsible for compliance under the CRC, their roles were much broader than this. Their remit covered all other corporate environmental compliance as well as energy efficiency: ${ }^{69}$

No, my remit really stems from looking after the utilities, so the main contract for buying electricity, gas and water, identifying all of the energy efficiency and low carbon projects and advising on new-builds. (CRC P5)

Therefore, all environmental compliance tends to be dealt with Energy Managers. These managers can also be the spearhead for corporate energy efficiency and contribute to the corporate strategy/ policy on energy:

However, only part of my work is delivering the operational sustainability objectives, and that can include engagement in issues around energy, energy efficiency, waste, water buildings and construction, resources, procurement, all those sorts of things, but also in developing strategies for the directorate, so developing things like waste strategies, Estates sustainability strategies, those sorts of things. (CRC P6, emphasis added)

I have all the environmental compliance and improvement activity, so I own the environment strategy, so if we decide to go for ISO 14000, all our pollution control, packaging compliance, any other kind of compliance to do with energy or carbon, like ESOS, for example, I do ESOS. Energy and Environment Manager, so it's anything in that field really. (CRC M16, emphasis added)

These individuals are not simply responsible for reporting energy data and purchasing allowances under the CRC. They have a direct responsibility for much bigger decisions on energy efficiency and they also feed into wider corporate policy. ${ }^{70}$ The consultants interviewed also offered strategy advice

\footnotetext{
68 I will use the term 'Energy Manager' from now on for simplicity.

${ }^{69}$ CRC M1, M4, M5, M7, M9, M10, M11, M12, M13, M14, M15, M16, P1, P2, P4, P5, P6, P7, and P8. For

example: 'I'm responsible for thinking up new projects that will improve the efficiency, energy efficiency of the university" (CRC P2); "it's working on the carbon reduction programme, looking for energy efficiency methods, working up projects that might bring bills down and emissions down further' (CRC M12).

${ }^{70}$ With the caveat that they have to get funding through their finance director/ board. However, the majority of the interviewees (that were participants as opposed to consultants/ solicitors) reported directly to senior management (ie the finance director) meaning that there was limited line management above them. The role of senior management will be considered below.
} 
to their corporate clients (CRC M3, M8), as well as solicitors advising on corporate responsibility strategy (CRC S1, S6).

This is compounded by the fact that senior management do not always take an active role in creating environmental strategies:

Yeah, [senior management] are, but you're being realistic and it's not high on their agenda. High on their agenda is, and with most organisations, its finance and your key aims. I do not think there are many organisations where the top decision is climate change. It is changing, but sometimes it is talked about a lot, but you do not really see any major commitment. (CRC P5)

In some cases, therefore, senior management is not driving energy reduction in businesses. A distinction was made between senior management in private companies and that in public bodies:

Private sector yeah, they definitely are engaged because at the end of the day they just see it as money. Especially the large organisations that like to showcase themselves as being the best, like L'Oréal, the Arkadium Group, that is good for them. But public sector there is no real incentive for director level to actually engage in sustainability, carbon reduction... (CRC M4)

Whilst they are aware that the CRC exists (as the CRC data is always reported to the 'highest level' (CRC P3) or 'all the way to the top' (CRC M8) in companies), they are not 'engaged at a level that they should or could be' (CRC P7), if they are engaged at all (CRC M4). ${ }^{71}$ Reputation has the potential to catch the attention of senior management and is probably a more accessible foundation of policy than a tax is.

The core involvement of senior management is therefore that they receive an annual report and sign a cheque to pay for the CRC. For example: 'I think the Chief Exec certainly does, because he's the guy that I sit with and he signs the cheque' (CRC M16); 'we did obviously engage with our finance office i.e. "Can we have some money please? Can we have a cheque?!"' (CRC P8). Beyond that it was difficult to get senior management to engage with the pure tax of the CRC:

I don't know if it's psychology but that's - that's how it seems to work. If you are relying completely on the tax, I don't think our Senior Management would get too excited unless it was something like $20 \%$. (CRC P4)

So, it's getting better but they [senior management] don't really understand what it is, and the hardest thing is to sell it to them, at the end of the day it's a tax. Because we can't turn round to them and say that charge actually achieves this because we don't know what it achieves. (CRC M1, clarification added)

The reality of this is that the Energy Manager is leading the conversations on energy efficiency at senior management level. The pure financial lever of the CRC does little on its own to inspire and engage senior management. The decision-making powerhouse on environmental matters is, for some companies, therefore devolved down to the Energy Managers: they make the decisions on compliance, energy reduction measures, and feed into corporate policy.

\footnotetext{
${ }^{71}$ CRC P2 stated that 'senior management is very on board, very much dedicated to reducing energy consumption and environmental impacts all round'. However, they were the only interviewee to be so positive about senior management engagement.
} 
Importantly, these Energy Managers are pro-environment. All but one interviewee believed in climate change when asked, and 29 out of 31 interviewees believed that more needed to be done to prevent climate change from getting worse. ${ }^{72} 30$ of the interviewees had an educational and/ or professional background in the environment, energy or sustainability. ${ }^{73}$ For these points of contact for the CRC, the environment (and climate change) is important:

As environmental consultants, I'm pretty sure all of us do worry about climate change. If any consultant comes into the firm now, they would have had exposure to climate change in academia and the impacts that can have on future generations. It would be impossible to say that we're not somewhat worried about that. (CRC M8)

Simon points out that a limit on rationality comes from 'the inability of the human mind to bring to bear upon a single decision all the aspects of value, knowledge, and behaviour that would be relevant" and that human rationality sits within "the limits of a psychological environment'. ${ }^{74}$ Within the organisational setting, the vast majority of the values that guide decision-making are rooted in the organisation's values. ${ }^{75}$ However, decision-makers in the organisational setting can still make choices that are based on an identification that is external to the organisation. ${ }^{76}$ In this case, those working with the CRC tend to hold strong environmental values and these too can creep into organisational decision-making; perhaps making them more inclined to go beyond compliance under the CRC. Therefore, in addition to the organisational constraints on rationality, the environment is special in the sense that it attracts individuals with strong values to the role. The decision-makers for the CRC, based in small teams in their host organisations, have environmental values that may predispose them to choose the more 'environmentally satisfactory' decision. This can be accentuated by the fact that businesses 'satisfice'. If an organisation only considers a few choices, then choice architecture could be used to highlight or emphasise more environmentally friendly choices with the addition of a social element to the scheme.

Through a combination of the facts that businesses cannot consider every measure and that their small energy teams are pro-environment, organisations could be susceptible to having their choices influenced. In particular, the highlighting of greener choices and policy pathways through additional tools, such as nudging, gives an additional tool to the Energy Manager's bow. By introducing these social norms to work alongside traditional regulatory measures provides for a stronger argument to adopt a greener policy or move beyond compliance; thus, influencing and shaping the decisions made by businesses and opening the door to nudging the powerful.

This article will now draw on the CRC data to explore two different methods of exploiting this irrationality: collaboration and competition. These two methods affect businesses through both internal (such as internal choice justification) and external drivers (such a damage to reputation) and indicate a potential role for social norms alongside more traditional regulatory approaches.

\footnotetext{
72 Interestingly, the only interviewee who did not believe in climate change was the only interviewee not to have an environmental background - their education was a postgraduate degree in trading standards (CRC M4).

${ }^{73}$ All six solicitors practiced in Environmental Law. The rest of the interviewees had either a working or academic background in the environment, including nine who specifically raised their postgraduate degrees. A range of these degrees include: sustainability, carbon and energy policy, climate change and risk management, and geography and environmental studies.

${ }^{74}$ Simon, Administrative Behavior (n 55) 108.

75 ibid 198.

${ }^{76}$ Such as a group identification or personal motives: ibid 205-206.
} 


\section{Discussion: Nudging the Powerful for Environmental Protection}

Just like other organisations, the organisations under the CRC are not rational. The potential to exploit this irrationality at both a macro and micro level means that it is worthwhile considering how choices could be shaped by policymakers. In particular, the CRC study would indicate that companies are susceptible to social nudges and that these could be used to highlight more environmentally friendly behaviour - in the case of the CRC, to drive participants beyond compliance. In the environmental context, nudges have often been bypassed for more interventionist measures to control pollution and other environmentally harmful behaviours. ${ }^{77}$ The core idea is that the 'social environment influences behaviour'. ${ }^{78}$ In particular, Thaler and Sunstein speak of the power of peer pressure - humans care what others think about them. ${ }^{79}$

The idea that a business could be driven by social norms emerged during the interviews in a number of forms. Interviewees often referred to the performance of others under the scheme - and, more importantly, a desire to perform better than their competitors under the scheme. As the CRC previously had a reputational element (in the form of the publicly available PLT), it is interesting that participants engage with and seek to know how others are performing under the scheme. The PLT is not the only performance table used by the Environmental Agency. Indeed, the Water and Sewerage performance assessment table and report note increases in the self-reporting of pollution incidents; $100 \%$ delivery of environmental improvement schemes; and, that pollution incidents damage reputation. ${ }^{80}$ Drawing on the CRC data, organisations also care what others think; $;{ }^{81}$ that they think it is right to comply with the CRC scheme; and that they do not want to be seen as underperformers.

Social norms 'matter for individual choices', 82 'as people are constrained by reputational forces and concern about the perception of others' ${ }^{83}$ They help us not only to understand behaviour, but also its regulation. ${ }^{84}$ The study data indicates that participants wish to avoid the consequences of external perceptions that they are not complying with the CRC. In later literature, building on Thaler and Sunstein's work, the concept of social norms has been developed to include further considerations. Sunstein and Reisch argue that if a chooser is aware that most other people are choosing green energy

77 Thaler and Sunstein (n 1) 193.

${ }^{78}$ Cass Sunstein, Why Nudge? (Yale UP 2014) 118.

${ }^{79}$ Thaler and Sunstein (n 1) 58-59.

${ }^{80}$ Environment Agency, 'Water and Sewerage Companies' Performance: 2017 Summary' (July 2018) <https://assets.publishing.service.gov.uk/government/uploads/system/uploads/attachment data/file/724027 Water company performance report 2017.pdf> accessed 12 May 2019

${ }^{81}$ I would like to distinguish the following discussion from the existing discussions in business literature of 'corporate greenwashing', which involves "forms of disinformation from organizations seeking to repair public reputations and further shape public images": William Laufer, 'Social Accountability and Corporate Greenwashing' (2003) 43 Journal of Business Ethics 253, 253. Instead, I am (perhaps naively) making assumptions that these social nudges will not result in corporations 'pretending' to be green. For more on corporate greenwashing see: Catherine Ramus and Ivan Montiel, 'When are Corporate Environmental Policies a Form of Greenwashing (2005) 44Business and Society 377; Ed Gillespie, 'Stemming the Tide of Greenwash' (2008) 18Consumer Policy Review 79.

${ }^{82}$ Anne-Lise Sibony and Alberto Alemanno, 'The Emergence of Behavioural Policy-Making' in Alberto Alemanno and Anne-Lise Sibony (eds), Nudge and the Law: A European Perspective (Hart 2015) 4; Cass Sunstein, 'Nudges.gov: Behavioural Economics and Regulation' in Eyal Zamir and Doron Teichman (eds), Oxford Handbook of Behavioural Economics and the Law (OUP 2014).

${ }^{83}$ Alberto Alemanno and Alessandro Spina, 'Nudging Legally: On the Checks and Balances of Behavioural Regulation' (2014) 12Intl J of Constitutional L 429, 430.

${ }^{84}$ Sibony and Alemanno (n 79) 4. See also Michael Vandebergh and others, 'Regulation in the Behavioural Era' (2011) 95 Minnesota L Rev 715. 
(for example), then they are far more likely to follow suit. ${ }^{85}$ Sunstein and Reisch also tackle the question of expression, arguing that, for some, their decisions are based upon a desire to express certain values (in this case being green - they want to 'make a statement'). ${ }^{86}$ Finally, signalling could drive behaviour, as people act if it improves their social status. ${ }^{87}$ Here, they point out:

Socially visible actions, such as driving electric sports cars, are naturally more useful for status signalling than switching to green electricity, installing a high efficiency heat pump in the basement, or opting for car sharing. 'Buying green' is often done for status reasons, while 'behaving green' is usually less visible and status-laden. ${ }^{88}$

This is problematic for using signalling as an exploitation approach under the CRC as being green is not as visible as, for example, switching to paper straws and biodegradable products. Under the scheme, participants are required to reduce energy consumption, but an external driver reliant on public perception has no status value unless this is publicised and engaged with. Nonetheless, it still feeds into a corporation's ability to justify their own actions internally. In this way, a social nudge could, for example, add weight to a new green project business case or build collaborative networks that help companies to justify to themselves the path that they are taking.

In terms of nudging and the CRC, the scheme used to have a reputational element in the form of the PLT. Another potential use of nudging can be seen in the publication of offences and civil penalties by the Environment Agency, or naming and shaming. ${ }^{89} \mathrm{It}$ is in light of these past reputational elements that the CRC interviewees alluded to a potential role for nudging the powerful. More specifically, ideas of collaboration and competition emerged from the interview data, demonstrating that reputation and social nudges have the ability to drive businesses to work together or against one another to gain an advantage. ${ }^{90}$ However, a key obstacle with the CRC (and almost certainly most environmental regulatory schemes) is that the success of a social nudge will depend on how well connected the environmentally unfriendly behaviour is with the public. That is to say that the public needs to be aware of and care about the behaviour to be changed - otherwise the organisation will not care. Without this, the impacts of a social nudge would be limited. This will be termed the 'connection'.

Overall, the data indicates that social norms could exploit the irrationality of businesses by playing on both the external and internal drivers outlined above. Through driving collaboration and inciting competition it is possible to influence and/or highlight the performance of companies; the social image portrayed by companies; or the business case for greener courses of action. Thus, driving companies to comply and move beyond compliance under the CRC. The use of external drivers (such as reputation) is only possible, however, where there is a reputational weight behind the social norm: it must be connected to the general public in order to be effective. The elements of collaboration, competition and connection will be considered in turn.

\subsection{Collaboration}

\footnotetext{
${ }^{85}$ Cass Sunstein and Lucia Reisch, 'Automatically Green: Behavioural Economics and Environmental Protection' (2014) 38Harvard Env L Rev 127, 129.

86 Ibid.

87 Ibid, 130.

88 Ibid.

${ }^{89}$ There is therefore an interesting intersection here between nudging and the use of sanctions. The use of informational nudges is probably a blend of a nudge and punitive function. Naming and shaming will be discussed in more depth later on in this paper.

90 See also Wagner (n 6).
} 
Humans left to their own devices do not necessarily cooperate. ${ }^{91}$ Yet, there are many positives to be gained from such cooperation; which tends to arise through stable policy and incentives for people to work together..$^{92} \mathrm{~A}$ social nudge, which has reputational consequences, has the potential to act as this incentive. In the case of the CRC, whilst the PLT did not state the sector of each organisation, the annual report publication that followed the PLT does. ${ }^{93}$ In addition, the PLT highlighted the name and trading name of the participants - making it simple for sectors to identify their peers.

Interviewees highlighted the start of a collaborative movement amongst participants in certain sectors, suggesting that the CRC may have prompted participants to come together. A difficulty with collaboration arises where it is challenging to relate to the different organisations. This is because, even within sectors, organisations are all different, with different reasons behind their emissions figures (CRC P5). Indeed, collaboration does appear to be limited by sector, as there is 'no point comparing apples with oranges' (CRC P2).

Collaboration can create a sense of community, however, with sectors coming together and working together:

And also I suppose the collaborative point is important, so we've talked to other companies, the other water companies; we do talk to each about the CRC and how it affects us and we come up with common points of feedback that get fed through the Water UK response. So that's another area where we've invested time to try and understand it between ourselves. (CRC M15, emphasis added.)

The water company example shows that Energy Managers have worked together to understand the CRC scheme, to better comply with the scheme. This collaboration spoke of joint efforts for both compliance and energy efficiency ideas (CRC M15), demonstrating a desire not only to comply but also internally justify actions: 'if water company $B$ is doing $X$, then we should too' for instance. Collaboration was also seen in other sectors (logistics, hospitality, and education). This practical observation builds upon existing psychological literature: that people are more influenced by the behaviour of those who are similar. ${ }^{94}$ That is, if sectors come together and collaborate, they would further be influenced by the behaviour of their fellow sector members, above the general influence of others in the CRC scheme.

Sharing ideas will also help engage and create behavioural change. The sense of community is an important one. In the agricultural sector, there appears to be a strong sense of community, with farmers knowing 'exactly what their neighbouring farmers are up to' (CRC R1). This sense of community could provide a stronger foundation for the use of disclosures - i.e. the publication of offences. What affects an individual in terms of reputation, might also affect a sector, facilitating further collaboration. Furthermore, sector-wide publication statistics could also act as a stronger foundation for competition (discussed in more depth below) as participants will not want to underperform when compared to their peers. It could bring a social norm into focus for a pub, say, that may not care what a retailer is doing, but is almost certainly interested in what its closest competitor is doing.

\footnotetext{
91 Peter John, Making Policy Work (Taylor and Francis 2011) 89.

92 ibid.

93 The Annual Report Publications, which publish raw emissions data, can be found here:

<https://www.gov.uk/government/publications/crc-annual-report-publications-phases-1-and-2> accessed 01 May 2019.

${ }^{94}$ Cialdini (n 31) 140; David Halpern, Inside the Nudge Unit: How Small Changes Can Make a Big Difference (WH Allen 2015) 114.
} 
If the trading scheme element of the CRC had continued and worked as a trading scheme, this would also have enabled collaboration between organisations (CRC M6). This may suggest that the abolition of the CRC by the government was premature. Thinking of what that nudge might look like is, however, a difficult task and it would have to walk the fine line between competition and collaboration. None of the potential social nudges put forward by interviewees would incite collaboration, ${ }^{95}$ and it would probably require sector level disclosure (for example to report on the performance of the hospitality sector, retail sector etc) to bring these sectors together in a collaborative way. ${ }^{96}$

\subsection{Competition}

Perhaps a more powerful driver is that of competition. A social nudge may, according to the interview data, also have the potential to improve performance and energy reduction through competition on two core levels. First, companies will not want to underperform or see themselves as underperformers compared to their fellow participants. Second, companies will not want to face any negative impacts on their reputation due to non-compliance.

It is perhaps easier to envisage a role for nudging that plays on the power of reputation and drives behavioural change to protect that reputation and avoid any associated negative consequences. This echoes wider literature on corporate social responsibility, which argues that:

There are characteristics of the industry in which the corporation is embedded, such as the level of competition therein, which can make corporations more likely to imitate what others are doing with respect to some set of policies. ${ }^{97}$

Businesses change their behaviour to preserve their reputation. ${ }^{98}$ As CRC M9 opines - 'when I worked for a bank we were largely driven by reputational issues'. Competition in itself can help 'fracture these high stakeholders and pit them against one another'. ${ }^{99}$ Participants strive to improve when compared against others, and this desire to improve equates to a behavioural change in terms of energy reduction. This is because, as a starting point, behaviour is greatly influenced by the perceived behaviour of other people; 100 and 'describing what most people do encourages others to do the same' ${ }^{101}$ As well as being able to see the behaviour of others, a reputational element also casts eyes onto the participant's own behaviour - and even just the suggestion that someone is watching has the potential to change behaviour. ${ }^{102}$ Additionally, a reputational element (such as a league table for example) allows one to perceive the behaviour of other people, it can also be used to demonstrate trends in behaviour and signal what 'most people do' ${ }^{103}$ It therefore facilitates organisations to justify

\footnotetext{
95 For example: 'You can almost give them like a, you know, like a washing machine type rating, you know, an $A$, a B a C-you know, something like that'. (CRC R1). This is a) far too interventionalist and b) looks very similar to the reputational element of the Performance League Table (discussed below).

${ }^{96}$ However, this would require a higher level of information collected by the Environment Agency and would require companies to either self-classify into a sector or be classified.

97 Sarah Soule, Contention and Corporate Social Responsibility (CUP 2009) 45.

${ }^{98}$ Although 'the importance of reputation varies across companies and sectors'. See work on corporate social responsibility: David Vogel, The Market for Virtue: The Potential Limits of Corporate Social Responsibility (Brookings Institution Press 2007) 53. This is echoed in wider, regulatory literature, which states that 'many business firms have been shown to respond to legal and regulatory values for a variety of other motives, such as protecting their reputations and social legitimacy': Gunningham and others (n 6) 21-22.

${ }^{99}$ This concept, found within competition-based regulation, resonates here: Wagner (n 6), 658.

100 Sunstein, 'Nudges.gov' (n 82).

101 BIT (n 32) 5.

102 Halpern (n 94) 119.

103 ibid, 21.
} 
their own actions internally by comparing them to others It also allows organisations to see the priorities and strategies of their competitors, which in turn could feed into their own strategies and policy.

The PLT was introduced at the start of the CRC scheme, and ranked participants in terms of their performance under the scheme. ${ }^{104}$ The PLT created a public reputational element to the scheme, whereby participants could compare and contrast their performance with others. In 2012, the government proposed the abolition of the PLT. ${ }^{105}$ The PLT received two main criticisms: 1 ) that the table was not presented in a format that easily allowed for comparison; and 2) that the table did not accurately portray information (ie the table was easily skewed). ${ }^{106}$ These criticisms were reflected in the interview data:

The [League Table] has to be tempered a little bit with, 'Yes, but we've been able to exclude this group and we've been able to exclude that group and maybe other people can massage their figures as well'. (CRC M13)

And;

I think the existence of a League Table was a good idea, the League Table as it stood didn't provide, wasn't usable, but I think that instead of just scrapping it they should have tried to improve it. But I think they thought it was too big of a challenge, so they gave up. (CRC P3)

Interviewee M13 explicitly highlights that the table could be skewed through the 'massaging' of data, whilst P3 accepts that the table in its original format was not useable. CRC M9 described the PLT as 'a distortion which created anomalies that were not really fair on organisations'. Some interviewees never bothered to look at the table (CRC P7); or only looked once or twice (CRC M11). The PLT was therefore not 'easy', it was not simple enough that participants could engage with the table. ${ }^{107} \mathrm{An}$ easy nudge reduces any 'hassle factor' and 'simplifies messages'. ${ }^{108}$ This was not the case with the PLT and there was the underlying concern that the data within the table could be tinkered with, meaning that participants could not take the table at face value.

Nonetheless, the government concluded that there was 'some evidence' that the PLT acted as a reputational driver. ${ }^{109}$ Interviewees discuss how the PLT drove competition:

There was this whole performance league table that was set up and there were concerns about corporate reputation and you would be competing to get to the top of it. (CRC M11)

There was quite a lot of engagement with it to see how they could differentiate themselves and use it to benefit their businesses and put them in a good state, competition-wise, against other companies (CRC S5)

\footnotetext{
$104<$ http://crc.environment-agency.gov.uk/pplt/web/plt/public/201112/CRCPerformanceLeagueTable20112012 > accessed 10 August 2014.

105 Department of Energy and Climate Change, 'Consultation on simplifying the CRC Energy Efficiency Scheme' (March 2012) 66.

${ }^{106}$ Department of Energy and Climate Change ,'Simplification of the CRC Energy Efficiency Scheme: Report of Stakeholder Events' (2012) 24-25.

$107 \mathrm{BIT}$ (n 32).

108 ibid 4.

${ }^{109}$ DECC, 'Consultation on simplifying the CRC Energy Efficiency Scheme' (n 102) 62.
} 
What is interesting is that CRC P3, along with around a quarter of interviewees, saw the removal of the PLT as having a negative impact on the scheme. Whilst the table as it stood was not viable, once removed, CRC M8 believed that the purpose of the scheme had also been removed, indicating that the reputational element of the scheme had the potential to drive behavioural change. The reputational element of the scheme was lost - 'it was better news when they thought that they could put themselves on a league table and have a better reputation as a consequence of the action they were taking' (CRC M12). Therefore, a social nudge that allows participants to compare their performance to others (like a PLT, or other ranking system) was deemed 'worthwhile' (CRC M13).

It also enables participants to track the progress of their own performance: 'it's useful for me to talk to my members and say, "Yeah. Yeah. We've moved so far up the league table"' (CRC M13). It provides performance reassurance and internally justifies organisational activity when they are performing well. This is an engagement with the environment at more than just an Energy Manager level. The PLT provided a springboard for discussion and brought the environment to the policy agenda for the Energy Managers.

The ability to compare progress, in turn, allows for competition between participants; with 'companies going against other companies trying to compete in how efficient they are' (CRC M8). This competition drives participants to want to be the best in their field and avoid underperformance: ${ }^{110}$

Some companies it's a big differentiator for them, so, for example, we do a lot with (another organisation), and I know, for them, they want to be a leader in this area because they are actually advisors on sustainability and energy efficiency, so they want themselves to be a leader in it, so it's a reputational thing for them. (CRC S1)

Certainly, amongst the real estate investor clients that I work with, there is a massive drive always to be top quartile of whatever it is that is being looked at. So, any CRC league table that had existed, all my clients would have wanted to be top quartile in it and, more importantly, they would all want to be able to say that they were higher than each other. So, I think that would have driven a lot of competition amongst people to actually generate savings and things. (CRC S6)

It was particularly important for larger companies that wanted to go beyond compliance and 'showcase themselves as being the best' (CRC M4). This desire to be better than their peers is the foundation of a reputational element, as they are presenting a particular, social image when eyes are on them, which they do not want to be tarnished. ${ }^{111}$ The PLT also had the ability to improve reputation:

But it was better news when they thought that they could put themselves on a league table and have a better reputation as a consequence of the action they were taking. But there we are. (CRC M12)

The removal of this reputational element was perceived as a negative by M12 in the sense that organisations now have less of a driver to go beyond compliance and reduce their energy consumption (as compliance under the CRC only required the reporting and purchase of allowances equal to energy consumed). The reputational drivers that came out of the PLT cannot be 'under-estimated' (CRC S6). If anything, one interviewee stated that they would strengthen 'the reputational programme side of

\footnotetext{
110 Just like businesses wanted to create the best chemical in competition-based regulation: Wagner (n 6) 658.

111 Halpern (n 94) 119.
} 
it [the CRC]' (CRC R1). Following on from this sentiment, it is potentially a shame that the PLT (and ergo the $(R C)$ was abolished.

The CRC data has illustrated several additional drivers that could shape corporate behaviour to both comply and go beyond compliance. Both collaboration and competition had the potential under the scheme to exert internal and external pressures on companies as they avoid both underperforming and the negative reputational consequences of environmentally unfriendly behaviour. However, exploiting social norms holds very little value (and would not drive corporate policy change) if it is not understood by the wider, general public. As such, an understandable connection needs to be forged between the environmentally unfriendly behaviour and the public. If the public understand and value the reduction in energy, then a company that does not engage in energy reduction could negatively affect their public image.

\subsection{Connection}

If we get all hot under the collar about something that the public don't care about, you are not really going to get the support. (CRC R1)

A reason why social norms can work is that people 'think that others are closely paying attention to what they are doing'; and as such, that their behaviour is under scrutiny and judgement from others. ${ }^{112}$ This is why Thaler and Sunstein argue that if choice architects are seeking a change in behaviour, then they could 'simply' publish the performance of others. ${ }^{113}$ This is all well and good in inciting competition and collaboration amongst the participants (who all hopefully understand the CRC), but this publication could have a wider impact on the reputation of the participant. If an organisation is concerned about its reputation, then a nudge will not be able to play on a company trying to avoid reputational harm unless there is a connection between the behaviour to be changed and the public.

The Environment Agency published any civil penalties or convictions arising from the CRC scheme. ${ }^{114}$ Between 2018 and 2019, only 10 civil penalties were listed on the gov.uk website. To put this figure into context, there are over 2000 participants of the CRC. Originally, he penalties are often published long after the year to which they relate (for instance, Aquaterra Leisure received a penalty of $£ 250$ for failure to surrender sufficient allowances for the 2013/2014 compliance year - this was published in January 2017; a failure to surrender allowances in the 2015/2016 compliance year was published in July 2019.). ${ }^{115}$ The publication is therefore not 'timely' - people are more responsive to costs and benefits that take immediate effect. ${ }^{116}$ The delay in receiving a penalty can affect the manner in which people respond to it especially if the penalty is received months or years before it was published. This creates a potential disconnect between the penalty, the publication and its potential to create negative social consequences for businesses.

\footnotetext{
112 Thaler and Sunstein (n 1) 65.

113 Ibid, 71.

${ }^{114}$ Civil penalties: <https://www.gov.uk/government/publications/climate-change-regimes-civil-penaltiesimposed/crc-energy-efficiency-scheme-civil-penalties> accessed 21 March 2017. The original transparency data on the publication of offences under the CRC was withdrawn on the $13^{\text {th }}$ November 2018.

${ }^{115}$ Environment Agency, 'CRC Energy Efficiency Scheme: evidence, audits and penalties'

$<$ https://www.gov.uk/government/publications/climate-change-regimes-civil-penalties-imposed/crc-energyefficiency-scheme-civil-penalties\#aquaterra-leisure> accessed 21 March 2017; Environment Agency, 'Climate Change Civil Penalties' < https://data.gov.uk/dataset/13c0893a-049a-4608-9f9b-7f268a71f15a/climatechange-civil-penalties $>$ accessed 21 August 2019.

${ }^{116} \mathrm{BIT}(\mathrm{n} 32) 6$.
} 
Whilst the publication of offences was argued to be 'particularly important' (CRC R1) by my interviewees; the disconnect between publication and interviewees have noted its impact:

I cannot recall any article whereby it's indicated that a certain entity has been prosecuted for failure to partake or register or submit annual reports or what's necessary to comply with the CRC. (CRC M14)

Whilst the penalties are published, they are not always obvious to participants. One interviewee recalled an email communication from the regulator, stating that 'fines had been issued', but that it was still 'really hard to judge' who and how many were receiving penalties (CRC M10). Sunstein argues that, as a 'rule of thumb', any disclosure should be 'concrete, straightforward, simple, meaningful, timely and salient' ${ }^{117}$ It is also important for a nudge to be salient to those being nudged. ${ }^{118}$ Indeed, 'sensible regulatory policies, especially those that involve disclosure, are attentive to the importance of salience. ${ }^{119}$ Without salience, people might ignore the feature that the regulator is trying to highlight: in this case, the regulator is trying to draw attention to non-compliance, yet it is not being engaged with. ${ }^{120}$ Participants are therefore not 'attracted' to the publications, lowering any potential negative reputational consequences and lowering its impact on compliance or as a policy driver.

In this case, energy reduction and/ or emissions reductions need to be 'socially relevant; it needs 'to be an issue that people are worried about' (CRC R1). This particularly poses a problem when dealing with the participants of the CRC. Whilst a number are high profile organisations, the rest either report under an organisation name that is different to their high-street trading name, ${ }^{121}$ or they are middle sized, unknown-to-the-public organisations:

Who cares whether a particular hospital has high emissions or who cares if a company that only sells to business has high emissions. So, I think it depends whether you're likely to be affected by publicity or not. (CRC M2)

It is difficult to drive policy change using social nudges and the power of reputation when most of the companies are not public facing. These companies are not as bothered about avoiding negative consequences that stem from non-compliance. Instead, it is possible to draw upon one advantage highlighted by CRC S6: who said that his/ her organisation was 'driven by our own desire to tell clients in our tenders and pitches that we were doing this kind of thing'. Also known as demand side drivers, these internal drivers hat can justify greener behaviour, place an emphasis on energy efficiency in winning work. This could make the connection between energy reduction and reputation for some organisations.

For those CRC participants that are public facing, the emphasis for social nudges needs to be on public disclosure (CRC M10). This could increase pressure on ensuring compliance at the micro level and driving shifts in corporate policy at the macro level. Any information that builds a picture of how the

\footnotetext{
117 Sunstein, 'Nudges.gov' (n 82) Chapter 28.

118 Ibid; BIT (n 29) 19; Thaler and Sunstein (n 1) 107; Sunstein, Why Nudge? (n 78) 9.

${ }^{119}$ Sunstein, 'Nudges.gov' (n 82).

120 Sunstein, Why Nudge? (n 78) 9.

${ }^{121}$ For example, Kingfisher PLC actually includes B\&Q, a well-known high street name. Kingfisher PLC is not a well-known high street name. Yet, Kingfisher PLC emitted 183933 tCO $_{2}$ in the 2013-2014 ARP (39 ${ }^{\text {th }}$ largest emitter (in terms of raw data) out of over 1935): Environment Agency, 'CRC Energy Efficiency Scheme Annual Report Publication 2013/14' (20 November 2014), available via: <https://www.gov.uk/government/publications/crc-annual-report-publication-2013-to-2014> accessed 21
} August 2019. 
company works can provide the public with a better understanding of how that organisation works (CRC P3).

Two initial hurdles come to mind. First, companies have the power to shape their own public relations strategy. If they are highly concerned by their public image, they could 'greenwash' their behaviour or elements of their behaviour to hide or detract from any environmentally unfriendly aspects. They could also spend resources highlighting other attractive features of their behaviour that are important to reputation, such as cost. They have the resources to do so and a social nudge does not stop them. ${ }^{122}$ However, Beder argues, 'empty rhetoric and coats of green paint no longer suffice in the field of reputation management'. ${ }^{123}$ Second, it requires a public understanding of the information being presented to them. In terms of the CRC, 'most people don't even know what it is' (CRC M1). Every single interviewee stated that they did not believe the layperson in the street would be aware of the CRC. ${ }^{124}$ The CRC therefore has a low profile. A resolution to this is to work towards 'one version of the truth':

I talked about if I designed a new scheme I would have clarity and a high level of disclosure. 'One version of the truth' is a term we often use, is really important, and that's what we should be aiming for. (CRC M10, emphasis added)

Letting go of specific scheme disclosure (in terms of public disclosure only) and simplifying disclosure into one understandable figure that translates across all energy efficiency schemes could take a step towards allowing the public to get to grips with energy efficiency. It would also allow companies to communicate clearer, more accessible green policies, or to be driven to do so by a more powerful disclosure mechanism. It is unclear whether the government intends to take this step in the short or long-term, but a single reporting mechanism and publication mechanism could improve public engagement.

Even if there was one method of portraying energy efficiency data, it would still be difficult to get the public to engage with that information. This is where technology, and specifically social media, could play a bigger role in nudging:

Brand and reputation which can be particularly damaged, as with social media, it is far easier to portray negative impressions for relatively small misdemeanours, so that's become much more important. (CRC S5)

Beyond the scope of the CRC, social media has a role to play in all energy efficiency schemes and taxes. The Environment Agency can publish offences and publish performance data on a readily accessible platform, which already has a wide audience. ${ }^{125}$ This is already done for other 'big offences' (notably

\footnotetext{
${ }^{122}$ For instance, Procter and Gamble spent $\$ 7.6$ billion on advertising in 2017. Siddharth Cavale, 'P\&G says cut digital ad spend by $\$ 200$ million in 2017’ (Reuters, 1 March 2018), <https://uk.reuters.com/article/us-proctergamble-advertising/pg-says-cut-digital-ad-spend-by-200-million-in-2017-idUKKCN1GD654> accessed 10 May 2019

${ }^{123}$ Sharon Beder, 'Environmentalists Help Manage Corporate Reputation: Changing Perceptions not Behaviour' (2002) 1(4) Ecopolitics 60.

${ }^{124}$ CRC M12 built on this with: 'It doesn't always mean anything to the person in the street. But they don't know what a kilowatt hour of energy is either. So, I don't think it really matters.' This would indicate that public awareness on energy full stop still has some way to go.

125 The Environment Agency has almost 529,000 followers on Twitter; almost 43,000 likes on Facebook; and even has an Instagram account. Twitter and Facebook follower figures accurate on 21 August 2019: <https://twitter.com/EnvAgency>; < https://www.facebook.com/environmentagency/> accessed 21 August 2019.
} 
involving rivers), ${ }^{126}$ yet, a search of the Environment Agency's tweets shows no such publication for any penalties issued under the CRC or even tweets on energy. ${ }^{127}$

It also requires the public to care about the environment for any negative impact on reputation to occur. Whilst environmental responsibility is one of the "major facets of reputation", it is "not the beall and end-all of reputation'. ${ }^{128}$ For some, the quality of products and services outweigh wider public responsibility concerns such as the environment or employee treatment. ${ }^{129}$ Nonetheless, products that are perceived as being environmentally friendly 'are being increasingly preferred by consumers'. ${ }^{130}$ Indeed, the environment is now an established element of the wider Corporate Social Responsibility of companies, which can enhance reputation. ${ }^{131} \mathrm{~A}$ social nudge, such as seen under the CRC, would highlight certain behaviours (such as energy consumption under the PLT) under the umbrella of the environment - an area that is increasingly important to the public.

If a connection is made between energy reduction and the reputation of the organisation, then naming and shaming can be a powerful social nudge to improve compliance. The connection to reputation brings the possibility of damage to a brand image, by calling out companies on environmentally unfriendly practices (which are a reflection of the corporate policies and priorities). It brings an additional tool to the table, above and beyond the tax already in place:

I think originally, when they were going to name and shame everybody and all of that, I thought it would have been good. But it's just a tax now, short and simple. (CRC P5)

Even with a connection to reputation, naming and shaming still relies on the organisation's views on publicity - 'some organisations will be unconcerned by bad publicity' (CRC P7). ${ }^{132}$ In terms of the PLT, there was some scepticism regarding the larger emitters: 'You know who the big polluters are, and they will always be that way' (CRC P5). Although, anomalies in the table can cause publicity:

\footnotetext{
${ }^{126}$ See for example a tweet from 22 ${ }^{\text {nd }}$ March 2017 by the Environment Agency: "\#ThamesWater ordered to pay record-breaking $£ 20$ million for polluting \#River Thames with 1.4 billion litres of raw sewage." <https://twitter.com/EnvAgency/status/844526162848239616> accessed 19 February 2019.

127 Twitter search conducted 21 August 2019. Separate searches of relevant hashtags (\#CRC, \#carbonreductioncommitment) showed a limited engagement in the private sphere, but no input from the Environment Agency: <https://twitter.com/search?q=\%23carbonreductioncommitment\&src=typed query> accessed 21 August 2019.

${ }^{128}$ Stewart Lewis, 'Reputation and Corporate Responsibility' (2003) 7Journal of Communication Management 356, 362.

${ }^{129}$ Graham Page and Helen Fearn, 'Corporate Reputation: What do Consumers Really Care About?' (2005) 45Journal of Advertising Research 305, 311.

${ }^{130}$ Krishna Udayasankar, 'Corporate Social Responsibility and Firm Size' (2008) 83Journal of Business Ethics $167,170-171$.

${ }^{131}$ Kathy Babiak and Sylvia Trendafilova, 'CSR and Environmental Responsibility: Motives and Pressures to Adopt Green Management Practices' (2011) 18Corporate Social Responsibility and Environmental

Management 11, 17.

${ }^{132}$ Relevant here is the idea of the regulatory paradox, or self-defeating regulatory strategies. It is a failure of the state to understand and predict how regulatees will adapt to regulatory approaches. For instance, if those that consumed the most energy under the CRC did not care about publicity, then exploiting reputation through social nudges would be a self-defeating regulatory strategy. In the case of the CRC, the biggest emitters under the scheme were generally high street names. Whilst there were a number of elusive holding companies under the scheme, the scheme did capture well-known, well-advertised companies, indicating that there is at least some role for reputation to play under the CRC. See Cass Sunstein, 'Paradoxes of the Regulatory State' (1990) 57University of Chicago L Rev407 (and in particular 412-429).
} 
I go back to the first year the company I worked for did its early action metrics and ended up as one of the top 22 companies and I remember there was a big hoo-ha because was it Virgin was right at the bottom? (CRC M2)

It is possible for participants to engage in a social nudge and pay attention to how other organisations are performing. For the core decision-makers under the CRC, this is another driver for compliance. At the broader, more macro level, the power of collaboration and competition could drive policy change in businesses, as those businesses work with and against one another in a bid to be seen to be green.

To conclude, social nudges could potentially exert internal and external drivers on companies to change their behaviour; whether that is from their own desire to be seen to be green; whether they are concerned about the consequences of negative publicity; or whether they just need help justifying their own actions.

This will especially be the case in a social nudge that incites collaboration, competition and connects the behaviour to the organisation's reputation. The competition engages participants in a reputational element, which gives them something additional to gain from good performance. By inciting collaboration, participants are working together as sectors to share ideas, which also promotes energy reduction. Any form of disclosure needs to make that link back to the reputation (be that to the public or other businesses), for without this, any impact on reputation would be limited and so would not further fuel beyond-compliance behaviour or shifts in corporate policy.

\section{Concluding remarks}

This article has drawn on an empirical study of the Carbon Reduction Commitment, a tax-like environmental scheme that ended in April 2019. Nonetheless, the CRC provides us with an illustration of alternative drivers that could shape organisational behaviour. It is a scheme where compliance does not necessarily equate with behavioural change. Therefore, additional drivers are potentially useful in pushing regulatees beyond compliance.

Organisations are not rational. Just like humans, they cannot consider every possible choice before them. In the environmental context, environmental staff teams in organisations tend to be small and pro-environment. Moreover, they play a key decision-making role and feed into the green policies and strategies of organisations. Irrationality could therefore be exploited on an individual decision level (micro level influence) but also at a policy level (macro level influence).

The CRC data further indicates that there is a role for social norms in exploiting the irrationality of organisations. In particular, this paper has considered the role of the Performance League Table and publication of offences under the CRC as reputational drivers. In response to these, it would appear that CRC participants were both working together and against one another. By inciting collaboration and competition, it is possible to identify a number of internal and external drivers in organisations. In particular, this study saw that companies were keen not to be underperformers in relation to their peers; they wanted to be able to justify their own actions internally; and they wanted to avoid the consequences of external perceptions that they were not behaving.

This article raises important questions as to the possibility of using social norms, or nudging, to push organisations beyond compliance and change their behaviour. The CRC data would indicate that it could be possible to nudge the powerful. It is a starting point for further research into more ways in which alternative regulatory drivers could be used to shape organisational behaviour.

\section{Acknowledgments}


I would like to thank David Campbell, Steven Vaughan, David Sheldon and the anonymous reviewers and editor for their invaluable input into this paper. I would also like to thank the Chartered Institute of Taxation for partially funding the empirical study that underpins this paper. All errors and omissions remain my own. 